\title{
FUNDAÇÃO E (DES)CAMINHOS DO DIREITO A PARTIR DO PENSAMENTO DE ARENDT
}

THE FOUNDATION OF LAW IN ARENDT'S THOUGHT

\author{
EDUARDO JOSE BORDIGNON BENEDETTI \\ Graduando em Direito pela Universidade Federal de Pelotas (UFPel). \\ Integrante do GEHAr - Grupo de Estudos Hannah Arendt (DFIL/IFISP/UFPel). \\ eduardoj.benedetti@gmail.com
}

SÔNIA MARIA SCHIO Doutora em Filosofia pela Universidade Federal do Rio Grande do Sul (UFRGS). Professora do Departamento de Filosofia do Insitituto de Filosofia, Sociologia e Política da Universidade Federal de Pelotas (DFil/IFISP/UFPel). Coordenadora do GEHAr - Grupo de Estudos Hannah Arendt (DFIL/IFISP/UFPel). soniaschio@hotmail.com

\section{RESUMO}

O pensamento político de Arendt (1906-1975) está comprometido com a preservação da pluralidade humana. Nesse sentido, demonstrar-se-á, por intermédio de uma fundamentação teórico-filosófica, histórica e com uma leitura conjuntural do pensamento arendtiano em diálogo com as acepções de Agamben, que os conceitos de lei e de fundação necessitam de uma nova fundamentação. Assim, a partir da atividade política, reservando papel central à ação humana, o Direito contemporâneo terá sua efetividade assegurada em relação às demandas atuais e futuras.

Palavras-chave: Arendt; Direito; Política.

\begin{abstract}
Hannah Arendt (1906-1975) political thought is engaged with the human plurality. In this sense, it will be demonstrated, through a theoretical and philosophical foundation and based on a historical and a cyclical reading of Arendt, also in dialogue with Agamben thought, the article argues that the legal system needs a new foundation in order to guarantee its effectiveness in relation to current and future demands.
\end{abstract}

Keywords: Arendt; Law; Politics. 


\section{SUMÁRIO}

INTRODUÇÃO; 1 A AÇÃO POLÍTICA, A LEI E AS ATIVIDADES HUMANAS; 1.1 A ação Política; 1.2 A lei e o Direito; 2 O EVENTO DA FUNDAÇÃO; 3 A MODERNIDADE E A FUNDAÇÃO DO DIREITO; 3.1 A Sociedade Moderna; 3.2 A possibilidade de um poder destituinte; CONCLUSÃO; REFERÊNCIAS.

\section{INTRODUÇÃO}

O pensamento político de Hannah Arendt (1906-1975), entre os diversos temas abordados, trata do espaço público, isto é, da vida conjunta que ocorre a partir da condição humana da pluralidade, concebida a partir do discurso e da ação. No centro da política, “jaz a preocupação com o mundo, não com o homem"1, pois é na artificialidade desse espaço comum que as obras humanas - símbolos e heranças simbólicas e materiais - são manifestadas. Assim, Arendt evidencia, na política, a necessidade de reflexão acerca do poder, da alteridade e da capacidade da imaginação para elaborar o novo no pensar, no querer e no julgar.

Nesse sentido, o texto explana os conceitos fundamentais no pensamento político de Arendt, como a ação (1) e lei (2), para discutir a acepção de Arendt acerca da fundação - tarefa necessária após as Revoluções que marcaram o início da modernidade (a Francesa em 1789 e a Americana em 1776). Dessa forma, com base no diagnóstico da Modernidade (a partir do século XIX) - e na leitura de Agamben sobre o pensamento de Arendt - objetiva-se discutir a possibilidade de uma nova fundação para o Direito na contemporaneidade.

\section{A AÇAO POLÍTICA, A LEI E AS ATIVIDADES HUMANAS}

\subsection{A ação política}

Os momentos de ruptura histórica (como são as revoluções, por exemplo) instauram um hiato a partir dos quais aquilo que foi não é mais suficiente para fornecer os critérios para

\footnotetext{
${ }^{1}$ ARENDT, Hannah. A promessa da Política. Trad. Pedro Jorgensen Junior. Rio de Janeiro: Difel, 2008. P. 158. 
avaliar o presente e o futuro. Assim, entre a libertação ${ }^{2}$ e a liberdade (para Arendt ser livre e agir é a mesma coisa), há um "abismo", que antecede o novo começo. Dessa forma, há um desmantelamento do pensamento e do julgamento ${ }^{3}$. Aos indivíduos, resta somente lidar com essa imprevisibilidade para retomar a ação e preservar a política ${ }^{4}$.

Para tanto, Arendt reconcilia Filosofia e política, indicando para a fundação da vida humana o pensar e o agir político. Em sua obra $A$ condição humana (1958), Arendt trata das atividades que compõe a chamada vida activa; a saber, o labor, o trabalho e a ação. 0 labor está associado às atividades imprescindíveis para manutenção da vida, que se exaurem em sua própria prática. De maneira contrária, o trabalho, relaciona-se à produção do mundo material; isto é, a fabricação "da infinita variedade de coisas cuja soma total constitui o artifi 'cio humano" 5 . Entretanto, sabendo que "é com palavras e atos que nos inserimos no mundo humano"6, a ação é responsável por possibilitar que cada cidadão, em sua singularidade, dialogue publicamente, possibilitando a eclosão do novo. Conforme Arendt:

\begin{abstract}
ao contrário da fabricação, a ação jamais é possível no isolamento. Estar isolado é estar privado da capacidade de agir. A ação e o discurso necessitam tanto da circunvizinhança de outros quanto a fabricação necessita da circunvizinhança da natureza (...). A fabricação é circundada pelo mundo, e está em permanente contato com ele; a ação e o discurso são circundados pela teia de atos e palavras de outros homens, e estão em permanente contato com ela ${ }^{7}$.
\end{abstract}

\footnotetext{
${ }^{2}$ Para Arendt, libertação e liberdade não se confundem; enquanto a primeira diz respeito à libertação da repressão e a garantia dos direito civis, a segunda se relaciona com a ação política (Cf. ARENDT, 2011, p.63).

${ }^{3}$ Os conceitos de pensamento e julgamento são definidos por Arendt em sua obra $A$ vida do espírito (1981). O pensamento, na concepção dela, é uma tarefa inescapável para o ser humano, sendo necessário um deslocamento em relação ao mundo exterior. Para além desse processo de interiorização, o pensar exige uma revisão do passado e o questionamento à tradição. Por sua vez, a faculdade de julgar ocorre após o pensar, tratando de discernir e particularizar os conceitos genéricos. Conforme Schio: "a capacidade de julgar [...] ocorre pela conjunção do pensamento com o fato ou com o questionamento novo, objetivando extrair dele uma apreciação. Ou seja, julgar é a forma de relacionar o pensamento com os objetos do senso comum. Dito de outra forma, o julgamento é a capacidade humana de discernir mesmo que não haja critérios prévios e prontos que possam auxiliar na escolha, restando apenas o próprio juízo individual" (2012, p.97).

${ }^{4}$ Segundo Arendt (2005, p.201), a etimologia do termo política remonta à pólis, isto é, a um espaço de plena autonomia em que os indivíduos experenciam a liberdade. Tendo em vista a "infinidade de intenções e propósitos em constante intersecção e interferência” (ARENDT, 1987, p.173), a política permeia todos os domínios da vida, sendo "um lugar privilegiado doe encontro entre os seres humanos únicos, com a capacidade de agir livremente, responsabilizar-se por seus atos, com o objetivo de viverem como seres humanos autênticos" (SCHIO, 2012, p.183).

${ }^{5}$ ARENDT, Hannah. A condição humana. Trad. Roberto Raposo. Rio de Janeiro: Forense Universitária, 2010. P. 149.

${ }^{6}$ Ibid., p.189.

${ }^{7}$ Ibid., p.201.
} 
Em virtude da contingência da ação, Arendt desenvolve uma concepção lacunar de tempo. A ação ocorre em um intervalo de tempo em que é possível marcar humanamente a temporalidade; é um "sendo" entre o passado e o futuro. Apesar de não haver uma perenidade estabilizadora, essa ação visa à continuidade do mundo humano. Segundo Pereira ${ }^{8}$, há uma lógica de permanente tensão que evidencia um modelo distinto de racionalidade em Arendt ${ }^{9}, \mathrm{a}$ saber, um pensamento em constante movimento.

Dessa forma, a condição humana da pluralidade é teorizada por Arendt como o fato que permite a manifestação da singularidade ${ }^{10}$, por meio da fala e do pensamento. Essa singularidade é a responsável por romper com os ciclos repetitivos da natureza; ou seja, a singularidade humana implica que as ações não se repetem ${ }^{11}$. A ação é imprevisível, pois é portadora de significados e sentidos provisoriamente constituídos:

0 fato de que o homem é capaz de agir significa que se pode esperar dele o inesperado, que ele é capaz de realizar o infinitamente improvável. E isto, por sua vez, só é possível porque cada homem é singular, de sorte que, a cada nascimento, vem ao mundo algo singularmente novo ${ }^{12}$.

A existência, enquanto bios polítikos, é relacional: necessita de um "quem", pois acontece para os outros e com os outros. Assim, ela representa desafios à manifestação da pluralidade e da singularidade, na medida em que depende também de condições externas aos atores. Essas condições dizem respeito tanto à existência de esferas pré-políticas (como a

8 PEREIRA, Geraldo Adriano. A "tensão" como um operador hermenêutico para uma racionalidade política em Hannah Arendt. Philósophos - Revista de Filosofia, Goiânia, v.11, n.1, 2006. P.99.

9 Conforme Pereira: "Desse modo, falar de tensões é aqui sugerido como um modo que Arendt tem de afirmar a diversidade, ou a pluralidade, a imprevisibilidade desta condição. Pensar um particular e ao mesmo tempo associá-lo a um conceito de coletividade, visualizar um retorno a um passado ainda novo, enfim, uma série de ambiguidades ou um modo de conceituar que não segue uma linha causal, determinista, mas se mantém tensa. Falar da "tensão" como uma luz hermenêutica, ou modo de ler uma filosofia política, em Arendt, é dizer que não há padrões absolutos, um sentido acabado, mas um pensamento em constante pensar, uma ação em constante atividade, uma abertura a uma outra "lógica" que não é causal - pelo contrário é tensa -, que sustenta uma racionalidade política peculiar, sui generis. E para se navegar neste suposto mar de "insegurança", uma faculdade faz-se importante tanto para os homens de pensamento quanto para os homens de ação, conectando-os a dois âmbitos humanos que se "auxiliam" pensar e agir" (2006, Op.cit., p.109).

${ }^{10}$ Segundo Arendt, a pluralidade diz respeito ao "fato de que os homens, e não o Homem, vivem na terra e habitam o mundo" $(1989$, p. 7). Assim, a pluralidade é constitutiva do próprio ser humano e comporta a singularidade: enquanto todos são iguais na humanidade, agem pluralmente.

${ }_{11}$ Para Arendt, a ação humana é caracterizada pela irreversibilidade e imprevisibilidade, pois "age sobre seres que também são capazes de agir, a reação, além de ser uma resposta, é sempre uma nova ação com poder próprio de atingir e afetar os outros" (ARENDT, 2010, p. 203).

${ }^{12}$ ARENDT, Hannah. Op.cit., p.191. 
família que pertence à esfera privada e a escola ${ }^{13}$, que é pré-política porque representa a transição para a esfera pública) quanto de uma garantia mínima - a ordem jurídica, que pertence à esfera política porque organiza as relações entre os humanos.

Envolta em uma cadeia de acontecimentos, a ação se atualiza pelos novos nascimentos que permite. A natalidade significa "o impulso que surge do primeiro começo, que é o nascimento, pode se estender a novos inícios, pela ação, através do empenho pessoal"14. Corroborando essa afirmação, Lafer afirma que a natalidade significa justamente que o segundo nascimento - a entrada no mundo de artificialismos humanos- ocorre pela ação ${ }^{15}$. Nesse sentido, Arendt propõe uma reflexão que "se coloca sob o signo da esperança e que vê na ação, que a natalidade enseja, a permanente e igualitária capacidade de começar algo novo"16.

A ação também representa a realização humana, uma vez que permite aos cidadãos nortearem a sua conduta, permitindo demonstrar, por meio de palavras e ações, as novas possibilidades. Cabe, entretanto, ressaltar que a realização da condição humana da pluralidade (e da singularidade, sua correlata) e a liberdade experimentada durante seu exercício - não relacionam a ação a uma necessidade ou um impulso instintivo, para a política. Então, o homem não vivencia a liberdade por uma necessidade natural, mas a atualiza pelo amor mundi, que “reúne-nos na companhia uns dos outros e, contudo, evita que colidamos uns com os outros" ${ }^{17}$.

A possibilidade de que ações políticas desenvolvam-se sob o signo da pluralidade elabora um espaço de estar entre. Segundo Arendt, o mundo comum é "constituído pelo conjunto dos espaços entre as pessoas, este mundo é formado por categorias interpretativas; “o mundo não é uma estrutura é um agir constante; o mundo é criado por ações”18. Enfim, o mundo sintetiza as heranças simbólicas e materiais, sendo ele - e não mais o homem - o centro da política.

\subsection{A lei e o Direito}

A experiência da polis grega é uma inspiração presente no pensamento de Arendt. Assim, sua concepção de lei foi diretamente influenciada pela demarcação entre o público e o privado.

\footnotetext{
${ }^{13}$ Diz-se que a escola é uma esfera pré-política, pois se privilegia as condições para a busca da liberdade, permanece vinculada ao âmbito privado.

${ }^{14}$ SCHIO, Sônia Maria. Hannah Arendt: história e liberdade: da ação a reflexão. Porto Alegre: Clarinete, 2012. P. 166.

${ }^{15}$ LAFER, Celso. Hannah Arendt: pensamento, persuasão e poder. Rio de Janeiro: Paz e Terra, 1979 . P. 29.

${ }^{16}$ ARENDT, Op.cit., 2010, p.349.

17 Ibid., p. 62.

${ }^{18}$ ARENDT, Hannah. Homens em tempos sombrios. São Paulo: Companhia das Letras, 1987. P.56.
} 
Na Grécia antiga, a lei tinha uma notada função espacial, ao demarcar fisicamente os espaços da polis. Ela era a responsável pelo estabelecimento de um espaço que, apesar de ser artificial, não apelava para qualquer força transcendente. A lei não tinha como objeto uma sociedade ideal, pelo contrário, existe em virtude das vicissitudes da realidade.

A lei é produto da atividade do homo faber, segundo Arendt, daquele que realiza atividades para fabricação de meios para um determinado fim. Dessa forma, é um suporte necessário à instabilidade da ação humana e à demarcação do espaço público. Conforme Arendt, os totalitarismos modificam a função da lei:

0 antissemitismo (não apenas o ódio aos judeus), o imperialismo (não apenas a conquista) e o totalitarismo (não apenas a ditadura) - um após o outro, um mais brutalmente que o outro - demonstraram que a dignidade humana precisa de nova garantia, somente encontrável em novos princípios políticos e em uma nova lei na Terra, cuja vigência desta vez alcance toda a humanidade, mas cujo poder deve permanecer estritamente limitado, estabelecido e controlado por entidades territoriais novamente definidas ${ }^{19}$.

No Totalitarismo, a norma deixou de ser uma diretriz objetiva de conduta e de organização. A fim de praticar a tarefa de doutrinar, de gerar comportamentos e não ações, a norma acabou sendo aquilo que a lei do movimento (uma lei da História, no stalinismo ou da Natureza, no nazi fascismo) determinava. O Totalitarismo rompeu com qualquer critério de razoabilidade, paradigma da Filosofia do Direito ${ }^{20}$.

A "nova lei da Terra" a que Arendt faz referência é a pluralidade, que permite elaborar um mundo comum em que o novo surge da diversidade e se expressa no momento da ação. Por isso, é necessária a existência de certos consensos. A lei tem uma função de promessa porque visa à ação futura - segundo ela a promessa é um "poder estabilizador"21, enquanto o sentimento de perdão se relaciona com a ação passada. Dessa feita, a autora também se aproxima de uma concepção sociológica de lei, tendo em vista que o Direito é entendido como o conjunto de normas, impostas por um grupo social - a ênfase aqui recai sobre os mecanismos para construção de consensos, os grupos que os legitimam, e não necessariamente sobre o Estado-, como condicionante das relações sociais ${ }^{22}$.

Para a pensadora, a obediência à lei é necessária para apoiar o governo, sendo, também, uma maneira de ingressar na comunidade humana:

\footnotetext{
${ }^{19}$ ARENDT, Hannah. Origens do Totalitarismo. São Paulo. Companhia das Letras. 1989. P. 13.

${ }^{20}$ LAFER, Celso. A reconstrução dos Direitos Humanos. Um diálogo com o pensamento de Hannah Arendt. São Paulo: Companhia das Letras, 1988. P. 47.

${ }_{21}^{21}$ ARENDT, Hannah. Op. Cit., 2010, p. 303.

${ }^{22}$ BRUHL, Henri Levy. Sociologia do direito. São Paulo: Martins Fontes, 1997.p. 20.
} 
Diz ela [Arendt] que a aceitação da norma não deriva nem da submissão voluntária, nem do reconhecimento teórico de sua validade. A aceitação da norma é uma consequência do desejo de jogar. Eu não posso entrar no jogo se não me submeter às suas regras, e como o desejo de jogar, na condição da pluralidade, é o desejo de viver, não há como escapar das regras do jogo. Com efeito, todo homem nasce numa comunidade com normas preexistentes, que ele aceita porque não há outro meio de ingressar no grande jogo da vida ${ }^{23}$.

Percebe-se que, em Arendt, a norma - segundo a formulação de Richard Flathman ${ }^{24}$ possui uma legitimidade condicionada. Ela só será válida caso torne manifestas as opiniões comuns que surgiram no curso de um evento ou de uma ação. A norma é apenas a forma cristalizada e verbalizada de um ato; ela é a preservação do poder que o agir conjunto gerou, estendendo-se para o futuro e possibilitando a noção de continuidade. Ao inserir a expectativa de futuro numa concepção lacunar do tempo, a lei não pode se adequar a qualquer condicionante além da garantia da perpetuidade do público.

A questão da legitimidade como condicionante da norma pressupõe um regime no qual a população se aproprie do espaço público. Por isso, para Arendt, não basta um regime em que a maioria absoluta da população esteja no poder - caso, por exemplo, das sociedades de massa, em que o consumo e a produção substituem a lógica da ação. Dessa feita,

a emancipação social não é equivalente a universalismo político, ao mesmo tempo em que não podemos considerar, a priori, a inclusão ideal de todos os indivíduos e grupos sociais no interior do espaço público uma conquista política completa. Hannah Arendt parece mais exigente: ou liberdade política significa, de um modo geral, o direito de ser um participante no governo ou não significa coisa alguma. Se não podemos organizar tal tipo de participação, nem recorrer a um modelo de representação que o incorpore, não conseguiremos constituir um espaço político ${ }^{25}$

A lei legítima, não é analisada apenas em relação à conformidade com o direito, mas em relação ao processo participativo. A teoria arendtiana, aplicada aos estudos jurídicos, representa a necessidade de intersecção entre os campos da Sociologia e da Filosofia do Direito, tendo em vista que norma e valor, para ela, estão necessariamente imbricados. Depreende-se, assim, que o zelo pelo mundo comum e a responsabilidade dos cidadãos por ele (amor mundi),

\footnotetext{
${ }^{23}$ LAFER, Celso. Op. Cit., 1988, p. 224.

24 Ver DRUCKER, Claudia Pellegrini. O destino da tradição revolucionária: auto-incompreensão ou impossibilidade ontológica?. In: MORAES, Eduardo Jardim de; BIGNOTTO, Newton. Hannah Arendt: diálogos, reflexões, memórias. Belo Horizonte: UFMG, 2003. P.144.

${ }^{25}$ CORREIA, Adriano. A questão Social em Hannah Arendt: apontamentos críticos. Revista de Filosofia Aurora, Curitiba, v. 20, n. 26, 2008, p. 110.
} 
exige mais do que a simples observância à lei. Arendt propõe uma ética de responsabilidade, que exige uma maneira pessoal de pensar e de agir $^{26}$, utilizando as faculdades humanas para repensar constantemente o julgamento e o exercício da própria regra.

\section{EVENTO DA FUNDAÇÃO}

Segundo Sarlet ${ }^{27}$, os Direitos Humanos possuem dupla fundamentalidade. Em uma perspectiva material, relacionam-se à necessidade de uma proteção jurídica reforçada, que os priorize até mesmo em detrimento de outras normas constitucionais. Por seu turno, a fundamentalidade formal trata da aplicabilidade direta ${ }^{28}$, pela qual o constituinte conferiu eficácia plena a esses direitos. Todavia, a distinção considera tais direitos enquanto um fato ontologicamente dado, tanto em uma perspectiva histórica quanto teórica.

Seja na crítica formulada aos Direitos do Homem em Origens do Totalitarismo (1951) ou em seus estudos acerca da revolução (1963), Arendt parte de um ponto de vista diverso, conjugando esforços para "desvelar a universalidade dos problemas que a semântica dos direitos humanos veio, na sociedade moderna, solucionar"29. Dessa maneira, Arendt tratou do problema da “fundação", abordando-o a partir das Revoluções Americana e Francesa.

As revoluções permitiram à grande maioria da população, que até então permanecia ligada exclusivamente às necessidades de sobrevivência (esfera privada), o acesso à esfera pública. Sobretudo na experiência francesa, essa ampliação possuiu como premissa a compaixão, e não a liberdade (isto é, a assunção de partilha de um mundo comum): "a compaixão elimina a distância, o espaço material entre os homens, onde se localizam os eventos políticos e todo o universo das relações humanas"30. A experiência americana é exemplar para a pensadora por

\footnotetext{
${ }^{26}$ SCHIO, Sônia Maria. Op.cit., 2012, p. 226.

${ }^{27}$ SARLET, Ingo Wolfgang. A Eficácia dos Direitos Fundamentais. Porto Alegre: Livraria do Advogado, 2005, p. 560.

${ }^{28}$ Conforme positivado no Art. $5, \$ 1^{\circ}$ da Constituição Federal: "As normas definidoras dos direitos e garantias fundamentais têm aplicação imediata".

${ }_{29}$ MAGALHÃES, Juliana Neuenschwander. 0 paradoxo dos Direitos Humanos. Revista da Faculdade de Direito - UFPR, Curitiba, n.47, p. 32.

${ }^{30}$ ARENDT, Hannah. Sobre a Revolução. São Paulo: Companhia das Letras, 2011. P. 68.
} 
estar comprometida primeiramente com a "implantação da liberdade e o estabelecimento de instituições duradouras" 31 .

Em sua análise, Arendt entende que, apesar da mudança ser uma constante no processo histórico ${ }^{32}$, somente a Revolução instaura um hiato capaz de transforar os rumos dos acontecimentos. As revoluções são os "eventos políticos que nos confrontam, direta e inevitavelmente, com o problema do começo". ${ }^{33}$. Conforme Lafer:

o principium agostiniano de criação do céu e da terra situa-se fora do tempo. Entretanto, o initium da comunidade, precisamente por causa do hiato entre o desastre (o passado) e a salvação (o futuro) não pode surgir ex nihilo. Daí, de acordo com Hannah Arendt, o paradoxo do ato livre da fundação, pois de um lado constitui o evento sem precedentes provocado espontaneamente por uma série nova (Kant) e, de outro exige, como justificativa para ser bem-sucedido, uma conexão com uma série precedente. 0 enigma da fundação, portanto, é o de como reiniciar o tempo dentro do inexorável contínuo do tempo ${ }^{34}$.

Em vista dessa lacuna temporal, Arendt admite que "quando os homens de ação, homens que queriam mudar o mundo, se deram conta de que tal mudança poderia realmente postular uma nova ordem das eras, o começo de algo sem precedentes, eles começaram a olhar a história à procura de ajuda"35. Os homens da revolução conheciam basicamente duas lendas de fundação, ambas Bíblicas: o Êxodo e a história contada por Virgílio, acerca de Enéias $^{36}$. Analisando as similitudes entre as duas, ela conclui que "ambas insistem em um hiato entre o fim da antiga ordem e o início da nova" ${ }^{37}$. Apesar da Revolução ser um "evento novo e inconexo irrompendo na sequência continua do tempo histórico" 38 , não significa o início automático de "novos tempos".

Esse período de transição é essencial para a fundação de um novo corpo político estável, influenciando decisivamente na compreensão de temporalidade. Conforme explica Drukcer:

\footnotetext{
${ }^{31}$ ARENDT, Hannah. Ibid., p. 76.

${ }^{32}$ ARENDT, Hannah. Crises da república. São Paulo: Perspectiva, 1999.

${ }^{33}$ ARENDT, Hannah. Op.cit., 2011, p. 17.

${ }^{34}$ LAFER, Celso. Op. Cit. 1979, p. 99.

${ }^{35}$ apud WAGNER, Eugênia Sales. Hannah Arendt e Karl Marx: o mundo do trabalho. São Paulo: Ateliê Editorial, 2002, p.144.

${ }^{36}$ Sobre o mito da fundação: "a fundação que agora ocorrera, pela primeira vez, em plena luz do dia, passível de ser testemunhada por todos aqueles que a presenciaram, fora, durante milhares de anos, objeto de lendas primordiais, através das quais a imaginação tentava devassar um passado e um evento que a memória não podia alcançar" (ARENDT, 2010, p. 164).

${ }^{37}$ ARENDT, Hannah. Op.cit. 2011, p.164.
}

${ }^{38}$ Idem. 
Se as experiências revolucionárias continuam sendo algo estranho ao cotidiano e se, novas formas, mais intensas, de participação não se institucionalizarem, é porque os instantes de participação ativa são uma suspensão do tempo ordinário, por definição raros e efêmeros. É como se ela [Arendt] visse a história como uma alternância entre instantes de ruptura e instantes de retorno à rotina, sem que seja possível uma fusão entre essas duas ordens ${ }^{39}$.

Então, a "sobrevivência" da liberdade após a ruptura depende da fundação de um novo corpo político. Considerando a adoção por Arendt de uma perspectiva republicana, a lei deve possuir a capacidade de ordenar esse corpo político, o qual atua a partir de uma concepção coletivista de poder (poder enquanto agir conjunto). De fato, a fundação, o começo, foi uma preocupação premente entre os revolucionários: “a questão principal para eles certamente não era como limitar o poder, e sim como estabelecê-lo, não como limitar o governo e sim como instaurar um novo" 40 , haja vista a eclosão de "um evento desconectado que irrompe dentro da sequência continua do tempo histórico" ${ }^{41}$.

Segundo Arendt, foi no momento de estabilização que a Revolução Francesa fracassou, apelando para ideias metafísicas e não políticas, por exemplo, a "vontade geral”, de Rousseau ${ }^{42}$. Em realidade, os revolucionários foram induzidos, por força da tradição, à procura de um absoluto para justificar o ato de fundação. Todavia, ao invés de recorrer a um ente superior, voltaram-se para uma retomada da tradição romana, em que a lex tratava da res publica ${ }^{43}$.

Ressalta-se, então, a necessidade de que a fundação não ocorra por qualquer espécie de "teologia política". Refere-se, pelo termo teologia política, ao conjunto de crenças que tendem a representar óbices à natalidade - a verdadeira fundação do novo. A radicalidade do pensamento de Arendt consiste em conferir à política autonomia para o estabelecimento de suas próprias bases:

\footnotetext{
${ }^{39}$ DRUCKER, Claudia. Op.cit., p. 197.

${ }^{40}$ ARENDT. Op.cit., 2011, p. 196.

${ }^{41}$ Idem.

42 Ibid., p. 175.

${ }^{43}$ Esse movimento é assim justificado por Arendt: "a história romana esteve sempre fundamentada na ideia de fundação, e nenhuma das grandes concepções políticas romanas, tais como autoridade, tradição, religião, lei etc., pode ser entendida sem uma compreensão profunda do grande efeito que marca o início da história e da cronologia romanas, o fato da urbs condita, da fundação da cidade eterna" (2011, p. 175). Assim, em Roma a autoridade era derivada do ato de fundação. A política "e, consequentemente, a lei romana, baseavam-se na tríade: autoridade, tradição e religião, que personificava a crença no caráter sagrado da fundação de Roma. Desta sacralidade da fundação emergia a autoridade mantida pela tradição. Observe-se que, na contemporaneidade, a tríade romana foi substituída pela crença no progresso e no futuro infindável”. SCHIO, Sônia Maria; PEIXOTO, Claudia Carneiro. O conceito de lei em Hannah Arendt. ethic@, Florianópolis, v. 11, n. 3, p. 289 - 297, 2012, p. 293.
} 
Contudo, se nós entendermos por secularização um evento que pode ser datado em um tempo histórico ao invés de uma troca de ideias, então a questão não é se a "astúcia da razão" de Hegel foi uma secularização da providência divina ou se a sociedade sem classes de Marx representa uma secularização da idade messiânica. 0 fato é que a separação entre a Igreja e o Estado ocorreu, eliminando a religião da vida pública, removendo todas as sanções religiosas da política e fazendo a religião perder aquele elemento político que adquiriu nos séculos em que a Igreja Católica Romana agiu como a herdeira do Império Romano ${ }^{44}$.

0 pensamento de Sieyes ${ }^{45}$ foi fundamental para os revolucionários por julgar que as leis deveriam se basear em um poder constituinte (que, portanto, enfrentasse o problema do início) e não simplesmente no poder constituído. Conforme o próprio jurista: "a nação existe antes de tudo, é a origem de tudo, sua vontade é sempre legal, ela é a própria lei; antes dela e acima dela somente existe o direito natural." ${ }^{46}$. Por sua vez, Arendt critica o conceito de soberania tanto como entrave à ação política genuína (no âmbito da articulação entre agentes políticos), quanto (em uma esfera macro) pela imposição de barreiras que desmentem a pluralidade enquanto "lei da Terra".

Da mesma forma, o problema da fundação estende-se ao Direito. Em relação aos Direitos Humanos, como a própria Arendt admite ${ }^{47}$, há a necessidade de positivação para garantir a eficácia. A Declaração dos Direitos do Homem e do Cidadão (1789), entretanto, tratou a expressão "povo", nos limites dos estados nacionais, enquanto entidade metafísica. Por seu turno, a Revolução Americana possui méritos em relação à experiência francesa. Segundo Arendt,

0 que salva o ato de iniciação de sua própria arbitrariedade é que ele traz dentro de si mesmo a própria norma, ou, mais precisamente, que o princípio e a norma (...) além de se relacionarem um com o outro, são também contemporâneos. 0 absoluto, do qual o começo deve derivar sua própria validade e que deve salvá-lo de sua inerente arbitrariedade, é a norma, que aparece no mundo ao mesmo tempo que o começo ${ }^{48}$.

\footnotetext{
${ }^{44}$ ARENDT, Hannah. 0 que é autoridade?. In: Entre o Passado e o Futuro. São Paulo: Perspectiva, 2005, p. 69-70.

${ }^{45} \mathrm{O}$ jurista francês foi um dos primeiros a mencionar o Poder Constituinte, em seu livro "Qu'est-ce que le tiers État?", e a defini-lo como aquele que estabelece a Constituição e assim cria os poderes que regerão a nação. Para mais detalhes, ver FERREIRA FILHO, Manoel Gonçalves. O Poder Constituinte. São Paulo: Saraiva, 1999.

${ }^{46}$ apud FERREIRA FILHO, Manoel Gonçalves. O Poder Constituinte. São Paulo, Saraiva: 1999, p. 14.

${ }^{47}$ ARENDT. Op. cit., 2011, p. 197.

${ }^{48}$ Ibid., p. 170.
} 
Nesse sentido, a ideia apresentada por Agamben acerca de um "poder destituinte", conforme introduzido a seguir (3.2), é resultado bastante direto das reflexões arendtianas acerca do problema do começo, bem como do diagnóstico dela acerca da Modernidade (3.1).

\section{A MODERNIDADE E A FUNDAÇÃO DO DIREITO}

\subsection{A sociedade moderna}

Em sua obra $A$ condição humana, Arendt aprofunda a distinção entre a esfera pública e a privada. Retomando a tradição antiga, baseada também em Benjamin Constante e Fustel de Coulanges, Arendt assinala o surgimento da polis a partir da contestação dos antigos de que o governo necessitava de uma ordem em que o estar junto fosse guiado pelo agir político. Assim, "a vitória sobre as necessidade da vida no lar constituía a condição óbvia para a liberdade da polis" ${ }^{49}$. Muito embora seja enfática na diferenciação entre essas esferas - ou ainda entre o que é próprio ao homem, idion, e o que é comum, koinon $^{50}$, a análise arendtiana não nega que exista uma relação de implicação entre essas esferas, na medida em que a liberação das necessidades do âmbito privado é necessária para a conquista da liberdade.

É decisiva, nessa diferenciação, a distinção entre as esferas de igualdade e de desigualdade, a saber, entre a esfera em que há sujeição aos comandos do outro e aquela em que não há comandantes e comandados, em que é experenciada a plena liberdade ${ }^{51}$. De maneira oposta, Arendt conclui que a política também é utilizada contra sua própria finalidade: “a liberdade em relação à política, como uma das liberdades básicas, utiliza tal liberdade e se retira do mundo e de suas obrigações junto a ele" ${ }^{52}$.

A partir da Modernidade, Arendt diagnostica a política enquanto uma função da sociedade. Diferentemente do espaço público, essa "sociedade" é constituída a partir da publicização de assuntos referes à sobrevivência, isto é, pertencentes à esfera privada. Segundo a pensadora, o capitalismo industrial e sua demanda por acumulação fez com que "a sociedade assumisse o disfarce de uma organização de proprietários que, ao invés, de requererem o acesso

\footnotetext{
${ }^{49}$ ARENDT, Hannah. Op.cit, 2010, p.37.

50 Ibid., p. 29.

51 Ibid., p. 39.

52 ARENDT, Hannah. Homens em tempos sombrios. Sobre a humanidade em tempos sombrios - Reflexões sobre Lessing. São Paulo: Companhia das Letras, 1987, p. 20.
} 
ao domínio público em virtude de sua riqueza, exigiram dele proteção para o acúmulo de mais riqueza"53.

Cabe ressaltar que, resultante de um hibridismo, o social não se constitui em uma esfera autônoma, sendo antes a deterioração desta ideia. Nesse sentido, Pitkin ${ }^{54}$, utiliza a metáfora do social como uma "bolha" crescente, avançando sobre o domínio político e impedindo experiências políticas genuínas. Posto a revisão que empreende do pensamento político clássico, o social é uma crítica direta ao Leviatã e à concepção do poder político a partir da relação governantes e governados ${ }^{55}$.

Enfim, para assegurar o crescente acúmulo de capital, a economia é promovida artificialmente à principal assunto público - estando, inclusive, subordinado aos padrões de produtividade. Assim, o social está baseado no crescimento artificial do natural ${ }^{56}$. Posto o seu hibridismo, o social é também assimilacionista; isto é, antes de promover a igualdade necessária à ação política, relega os grupos a seus interesses e pressões. Essa "sociedade de massas" 57 , por sua vez, engendra uma cultura de massas - a cultura é reduzida ao entretenimento e seu consumo é instantâneo.

O social também significa a impossibilidade de articulação para objetivos comuns, gerando uma alienação do mundo comum. Na Sociedade as pessoas se unem por necessidades naturais e não mais pelos vínculos intersubjetivos:

A ascensão da sociedade trouxe consigo o declino simultâneo das esferas pública e privada; mas o eclipse de um mundo público comum, fator tão crucial para a formação da massa solitária e tão perigoso na formação da mentalidade, alienada

\footnotetext{
${ }^{53}$ ARENDT. Ibid., p. 83.

${ }^{54}$ PITKIN, Hannah Fenichel. The Attack of the Blob: Hannah Arendt's Concept of the Social. Chicago: University of Chicago Press, 1998.

55 DEGRYSE, Annelies. The Sovereign and the Social: Arendt's Understanding of Hobbes. Ethical Perspectives: Journal of the European Ethics Network. Londres, v.15, n.2, 2008, p.240.

${ }^{56}$ ARENDT. Op. Cit., 2010, p. 57.

${ }^{57}$ Conforme Arendt: "a dupla perda do mundo - a perda da natureza e a perda da obra humana no senso mais lato, que incluiria toda a história - deixou atrás de si uma sociedade de homens que, sem um mundo comum que a um só tempo os relacione e separe, ou vivem em uma separação desesperadamente solitária ou são comprimidos em uma massa. Pois uma sociedade de massas nada mais é que aquele tipo de vida organizada que automaticamente se estabelece entre seres humanos que se relacionam ainda uns aos outros, mas que perderam o mundo outrora comum a todos eles." ARENDT, Hannah. O Conceito de História - Antigo e Moderno. In: Entre o Passado e o Futuro. São Paulo: Perspectiva, 2005. P. 126.
} 
do mundo, dos movimentos ideológicos de massas, começou com a perda, muito mais tangível, da propriedade privada de um pedaço de terra neste mundo ${ }^{58}$.

A despeito do diagnóstico da Modernidade, Arendt reafirma as potencialidades da ação política: "a instrumentalização da ação e a degradação da política como meio de atingir outra coisa jamais chegaram a suprimir a ação, a evitar que ela continuasse a ser uma das mais decisivas experiências humanas, nem a destruir por completo a esfera dos negócios humanos" ${ }^{29}$. Arendt cita a transformação das ciências naturais em ciências de processo (irreversíveis e ilimitadas, segundo ela), enquanto exemplo de que a atividade humana da ação não é estritamente teórica ou contemplativa, tratando-se da capacidade efetiva de agir e de realizar plenamente a condição humana. Para tanto, é necessária uma refundação do poder político - na hipótese aqui desenvolvida, um poder destituinte.

\subsection{A possibilidade de um poder destituinte}

Apesar de criticada entre os comentadores, a noção da esfera social, e, principalmente, a constatação da publicização da esfera privada na Modernidade, é uma das importantes contribuições arendtianas ao pensamento político contemporâneo, além de questionar as distinções políticas tradicionais (como direita e esquerda). Ao inaugurar sua série Homo Sacer, Agamben (1995) afirma que pretende desenvolver o diálogo entre as reflexões acerca do campo de concentração, desenvolvidas por Arendt em Origens do Totalitarismo, e o método arqueológico de Foucault. Dessa forma, ele retoma a ideia grega de dupla significação da palavra vida. Portanto, ao ser referir ao imperativo da necessidade - a vida pela sobrevivência, trata-se da zoe; em contrapartida, quando se trata de um modo de vida, da escolha livre das necessidades, tem-se a bios (na terminologia arendtiana a vida no "mundo comum") ${ }^{60}$.

Entretanto, o homem moderno parece ter rompido com essa dualidade. Conforme constatou Foucault, a partir da biopolítica ${ }^{61}$, “o homem moderno é um animal em cuja política

\footnotetext{
${ }^{58}$ ARENDT. Op. Cit. 2010, p. 333.

59 Ibid., p. 242.

${ }^{60}$ Segundo Werner Jaeger: "foi o apelo de Sócrates ao "cuidado da alma” que realmente levou o espírito grego a romper caminho em direção à nova forma de vida. Se o conceito da vida, do bios (que designa a existência humana, não como um simples processo temporal, mas como uma unidade plástica cheia de sentido, como uma forma consciente de vida) ocupa doravante uma posição de tão grande relevo na filosofia e na ética, é a vida real do próprio Sócrates que, numa parte muito considerável, isso se deve" (2001, p. 534).

${ }^{61} \mathrm{O}$ termo biopolítica "surgiu, pela primeira vez, no pensamento de Foucault, numa palestra proferida no Rio de Janeiro, intitulada O Nascimento da Medicina Social. 21 Contudo, foi só com a publicação de A
} 
está em questão a sua vida de ser vivente" ${ }^{\text {62 }}$; isto é, no qual os fenômenos da vida humana passam a implicar-se no saber-poder. Assumindo a influência foucaultiana para pensar o poder não em sua forma jurídico-institucional, mas a partir de sua capilaridade nas relações humanas Agamben desenvolve uma caracterização da política moderna:

[...] não é tanto a inclusão da zoé na polis ... O decisivo é, sobretudo, o fato de que, lado a lado com o processo pelo qual a exceção se torna em todos os lugares a regra, o espaço da vida nua, situado originalmente à margem do ordenamento, vem progressivamente a coincidir com o espaço político, e exclusão e inclusão, externo e interno, bíos e zoe, direito e fato, entram em uma zona de irredutível indistinção ${ }^{63}$.

Sendo assim, depreende-se que, para Agamben, a vida nua (zoe) não foi simplesmente excluída da política; pelo contrário, foi politizada por aquilo que ele denomina de "exclusão inclusiva" 64 , fundando a chamada "cidade dos homens" (a polis, por oposição ao oikos). 0 relativo abandono da "vida nua" constitui a relação política originária; isto é, uma relação limite em que as pessoas são incluídas na comunidade politica puramente em virtude de sua exclusão. Então, a “vida nua” não é simplesmente excluída da política: antes é constituída por ela fundando uma relação biopolítica desde a gênese. Logo, a vida nua é politizada pela sua exclusão.

Considerando a atualidade dos Totalitarismos $^{65}$, para Agambem a pretensão de domínio total ocorre, em termos biopolíticos, a partir da assunção da "vida nua" pelo Estado Moderno, sendo alçada a objeto da política estatal, e, por consequência, surge "como o paradigma oculto do espaço político da modernidade, [...]"66. Assim, o paradoxo exclusão-inclusão não é mais válido, posto que foi a própria exclusão da vida biológica da política moderna que fez com que o

\footnotetext{
Vontade de Saber (1976) e, depois, com os cursos ministrados no Collège de France, intitulados Em Defesa da Sociedade (1975-1976), Segurança, Território e População (1977-1978) e Nascimento da Biopolítica (1978-1979), que Foucault dá a importância e a amplitude que esse conceito merece”. DANNER, Fernando. O Sentido da Biopolítica em Michel Foucault. Revista Estudos Filosóficos, n 4, 2010. P.143.

${ }^{62}$ AGAMBEN, Giorgio. Homo Sacer. O poder soberano e a vida nua I. Belo Horizonte: UFMG. 2004. P. 11.

${ }^{63}$ Ibid. p. 16.

64 "A política existe porque o homem é o vivente que, na linguagem, separa e opõe a si a própria vida nua e, ao mesmo tempo, se mantém em relação com ela numa exclusão inclusiva" (AGAMBEN, 2004, p.16).

${ }^{65}$ Segundo ARENDT: “As soluções totalitárias podem muito bem sobreviver à queda dos regimes totalitários sob a forma de forte tentação que surgirá sempre que pareça impossível aliviar a miséria política, social e econômica de um modo indigno do homem" (1989, p.511)

${ }^{66}$ AGAMBEN, Op.cit., 2002, p.129.
} 
homem estivesse em plena relação com o poder que antes ele excluiu. Conforme Agambem esclareceu em entrevista ${ }^{67}$ :

Minhas investigações mostraram que o poder soberano $\left[{ }^{68}\right]$ se fundamenta, desde a sua origem, na separação entre vida nua (a vida biológica, que, na Grécia, encontrava seu lugar na casa) e vida politicamente qualificada (que tinha seu lugar na cidade). A vida nua foi excluída da política e, ao mesmo tempo, foi incluída e capturada através da sua exclusão. Neste sentido, a vida nua é o fundamento negativo do poder. Tal separação atinge sua forma extrema na biopolítica moderna, na qual o cuidado e a decisão sobre a vida nua se tornam aquilo que está em jogo na política. O que aconteceu nos estados totalitários do século XX reside no fato de que é o poder (também na forma da ciência) que decide, em última análise, sobre o que é uma vida humana e sobre o que ela não é.

Se, a partir da Modernidade, a política deixa de ser uma atividade específica (preservar a boa vida) para existir em razão da vida (proteção da vida natural), esse fato também se reflete em relação ao Direito. Nesse sentido, as próprias Declarações de Direito - ao vincularem o nascimento a um território enquanto possibilidade de pertencimento a uma ordem jurídica fazem de um fato biológico uma categoria política. Assim, é a articulação entre a vida “matável” e a "insacrificável” que articula e indetermina a política moderna.

Dessa feita, os direitos humanos assumem dupla função: tanto asseguradores da liberdade quanto manifestações de uma racionalidade fundada precisamente naquilo que os antigos tinham excluído do âmbito público: a vida natural ${ }^{69}$. A política, então, passa a ser estritamente um meio para assegurar a vida biológica, afirmando o poder soberano ${ }^{70}$ e criando uma sociedade

\footnotetext{
${ }^{67}$ AGAMBEN, Giorgio. Entrevista com Giorgio Agamben. In:Instituto Humanitas Unisinos. São Leopoldo, 30. Ago.2012. Disponível em: http://www.ihu.unisinos.br/noticias/512966. Acesso em: 17. Set.2015.

${ }^{68}$ A ideia de "poder soberano" defendida por Agamben difere daquela desenvolvida por Arendt (exposta no capítulo 02 deste texto). Para ele, retomando o contratualismo hobbesiano: "É importante notar, de fato, que em Hobbes, o estado de natureza sobrevive na pessoa do soberano, que é o único a conservar o seu natural ius contra omnes. A soberania se apresenta, então, como um englobamento do estado de natureza na sociedade, ou, se quisermos, como um limiar de indiferença entre natureza e cultura, entre violência e lei, e esta própria indistinção constitui a específica violência soberana" (AGAMBEN, Op.cit., 2014, p. 40).

${ }^{69}$ A vida natural é um corpus: "é singular que em seu centro não esteja nem o velho sujeito das relações e das liberdades feudais, nem o futuro citoyen, mas o puro e simples corpus. Corpus é um ser bifronte, portador tanto da sujeição ao poder soberano quanto das liberdades individuais." (AGAMBEN, 2004, p. 129).

${ }^{70}$ Agamben afirma: "a implicação da vida nua na esfera política constitui o núcleo originário - ainda que encoberto - do poder soberano. Pode-se dizer, aliás, que a produção de um corpo biopolítico seja a contribuição original do poder soberano. A biopolítica é neste sentido, pelo menos, tão antiga que a exceção soberana. Colocando a vida biológica no centro de seus cálculos, o Estado moderno não faz mais, portanto, do que reconduzir à luz o vínculo secreto que une o poder à vida nua, reatando assim (segundo uma tenaz correspondência entre moderno e arcaico que nos é dado verificar nos âmbitos mais diversos) com o mais imemorial dos arcana imperii"(2004, p.12).
} 
dominada pelo animal laborans; isto é, em que a relação com o mundo é mediada somente pelo consumo, que "não pode absolutamente saber como cuidar de um mundo e das coisas que pertencem de modo exclusivo ao espaço das aparências mundanas, visto que sua atitude central ante todos os objetos, a atitude do consumo, condena à ruína tudo em que toca" ${ }^{\text {"71. }}$

Apesar da notada influência de Arendt no pensamento de Agamben, enquanto a pensadora retoma o pensamento grego, e a clara diferenciação entre público e privado, o italiano pensa que essa separação é, em si mesma, uma implicação biopolítica. Enfim, ressalvadas as diferenças tornam-se evidentes as similitudes no diagnóstico referente a Modernidade a partir da reprodução apolítica da vida.

Então, a análise de Arendt acerca das displaced persons (apátridas) ${ }^{72}$, parece uma manifestação histórica do "homo sacer"; isto é, daquele que se inclui na legislação na medida em que está fora dela. Além disso, ambos os pensadores confirmam a constatação de que a associação dos direitos do homem exclusivamente ao estado nacional, acaba por torná-los um formalismo vazio. Conforme Arendt:

Nenhum paradoxo da política contemporânea é tão dolorosamente irônico como a discrepância entre os esforços de idealistas bem-intencionados, que persistiam teimosamente em considerar inalienáveis os direitos desfrutados pelos cidadãos dos países civilizados, e a situação dos seres humanos sem direito algum ${ }^{73}$.

Para assumir uma forma jurídica, a vida nua, é incorporada ao ordenamento legal a partir de uma abstração da ideia de ser humano. A realidade dos campos de concentração comprovou fatalmente que a "nudez abstrata" do ser humano é o maior risco que se corre ${ }^{74}$. 0 pensamento arenditano esclarece que, se baseado em um legalismo abstracionista, o direito permite o descarte de vidas humanas como se fossem supérfluas, bastando que "sejam elencados motivos

\footnotetext{
${ }_{71}^{71}$ ARENDT, Op.cit., 2005, p.264.

72 A expressão diz respeito a pessoas sem nacionalidade. Conforme Arendt: "a expressão displaced persons foi inventada durante a guerra com a finalidade única de liquidar o problema dos apátridas de uma vez por todas, por meio do simplório expediente de ignorar sua existência" e, ainda, "muito mais persistente na realidade e muito mais profundas em suas consequências têm sido a condição de apátrida, que é o mais recente fenômeno de massas da história contemporânea, e a existência de um novo grupo humano, em contínuo crescimento, constituído de pessoas sem Estado, grupo sintomático do mundo após a Segunda Guerra Mundial” (ARENDT, 1989, p. 310).

${ }_{73}^{73}$ ARENDT, Hannah. Op.cit., 1989. p. 312.

74 Para mais detalhes acerca da análise dos Campos de Concentração, ver ARENDT, 1989, p. 333 e seguintes.
} 
aparentemente razoáveis - como na contemporaneidade, o "terrorismo" - para que os direitos humanos deixem de ser efetivos e possam ser "esquecidos" ou contornados"75.

Em suma, ressalvadas as diferenças, ambos os pensamentos convergem na afirmação de que, a partir da Modernidade, a política deixa de ser uma atividade específica para existir em razão da vida (proteção da vida natural). Como alternativa, os sujeitos políticos do presente (representados pelos novos movimentos dos humanos, em conjunto) podem constituir aquilo que Agamben - inspirado pela "potência destituinte" referida por Benjamin em seu ensaio On the Critique of Violence - chama de "poder destituinte": “enquanto um poder constituinte destrói a lei apenas para recriá-la sob uma nova forma, o poder destituinte, na medida em que depõe de uma vez por todas a lei, pode realmente abrir uma nova época histórica"76.

Trata-se, então, de uma forma de poder que não esteja vinculada à dialética de constituição e de desconstituição de regimes (e leis), necessitando também de estratégias próprias. A formulação do poder destituinte permanece esboçada preliminarmente na obra de Agamben e de outros contemporâneos ${ }^{77}$. Dessa forma, a confluência de perspectivas é essencial para a efetividade da reflexão em relação aos Direitos Humanos enquanto questão ético-politica, sobretudo para fomentar novas formas de relação e de interação entre os atores políticos. Assim, a "comunidade que vem"78 é aberta a uma singularidade em si mesma - isto é, à possibilidade de "ser qualquer coisa que seja".

Dessa forma, retomando Arendt, a ação política possibilita conjugar a pluralidade e a singularidade: "a pluralidade é a condição da ação humana porque somos todos os mesmos, isto é, humanos, de tal modo que ninguém jamais é o mesmo que qualquer outro que tenha vivido,

\footnotetext{
${ }^{75}$ SCHIO, Sônia Maria; PEIXOTO, Claudia Carneiro. Op.cit., 2012. p. 291.

${ }^{76}$ AGAMBEN, Giorgio. Como a obsessão por segurança muda a democracia. In: Le Monde Diplomatique - Brasil. Disponível em: <http://www.diplomatique.org.br/artigo.php?id=1568>. Acesso em: 28.Mai.2015. 77 Agamben afirmou, em recente entrevista, que: "se trata de un concepto que apenas comienza a aparecer en la reflexión política contemporánea. Tronti se refiere así en una entrevista a la idea de un "poder destituyente" sin llegar a definirlo de modo alguno. Partidario de una tradición en la que la identificación de una subjetividad era el elemento político esencial, él parece vincularlo al crepúsculo de la subjetividad política. Para nosotros, que partimos del crepúsculo y del cuestionamiento del concepto mismo de subjetividad, el problema se formula en términos diferentes".

Agamben, Giorgio. Elementos para una teoría de la Potencia Destituyente. Disponível em:

<http://artilleriainmanente.blogspot.mx/2015/03/giorgio-agamben-elementos-para-una.html?m=1>. Acesso em: 28.Mai.2015.

${ }^{78}$ Agamben, Giorgio. A comunidade que vem. Trad. Antônio Guerreiro. Lisboa: Editorial Presença, 1993.
} 
vive ou viverá [isto é, na singularidade]." ${ }^{\text {79 }}$ Em suma, exercendo o espírito arendtiano de pensar o novo e o inesperado, explicita-se se as potencialidades para que os sujeitos políticos do presente (representados pelos novos movimentos dos humanos, em conjunto) constituam um autêntico "poder desconstituinte". Dessa forma, mais importante do que pensar a política a partir de certezas, é acreditar que, a despeito da sociedade de massa, é possível a “invenção de novas formas de exercício da política e de novas formas de pensamento, capazes de recapturar e retraduzir em um instante a origem democrática da política" ${ }^{80}$.

\section{CONCLUSÃO}

A premissa desenvolvida por Arendt do “direito a ter direitos”, em sua obra, é a expressão fundacional de uma forma de reconhecimento, ancorada na demonstração da intersubjetividade dos atores políticos. O ser humano, nesse viés, possui apenas um direito que transcende todos os demais: o de nunca ser excluído da participação na comunidade, pois, se “excluído da participação na gerência dos negócios públicos que envolvem todos os cidadãos, o indivíduo perde tanto o lugar a que tem direito na sociedade quanto a conexão natural com os seus semelhantes." ${ }^{\prime 1}$. Constitui-se, então, "uma identidade sem a pessoa, na qual o espaço da política e da ética perde o seu sentido e tem de ser pensado a partir do zero"82. Por isso, retoma-se a desafiadora tarefa de pensar e de viver com uma consciência fragmentada, buscando reconstruir o pensamento em momentos de crise.

O diagnóstico acerca das limitações ao real exercício político, exposto por Agamben, retoma as críticas de Arendt aos fundamentos do constitucionalismo francês e a formação da vontade política. Torna-se, então, premente a necessidade de prestar maior atenção às potencialidades dos movimentos sociais enquanto espaços de “criação" da política. Esses movimentos possuem condições para a formação e para a multiplicação de espaços para novas formas de relação e de interação entre os atores.

\footnotetext{
${ }^{79}$ ARENDT. Op. cit., 1989, p. 8.

80 DUARTE, André. Hannah Arendt e a modernidade: esquecimento e redescoberta da política. Trans/Form/Ação, Marília ,v. 24, n.1, 2001, p. 269.

${ }^{81}$ ARENDT. Op.it. 1989. P. 170.

${ }^{82}$ AGAMBEN, Giorgio. Como a obsessão por segurança muda a democracia. In: Le Monde Diplomatique - Brasil. Disponível em: <http://www.diplomatique.org.br/artigo.php?id=1568>. Acesso em: 28.Mai.2015.
} 
Ademais, a retomada das categorias do pensamento político arendtiano e de seus interlocutores propicia a reavaliação dos elementos basilares do "estado de Direito", especificamente no que tange às noções de comunidade política e de cidadania. Também é possível abordar problemas cruciais, por exemplo, referente aos Direitos Humanos, como a tensão entre o universalismo e o relativismo, a relativização do princípio da soberania estatal e a redução os direitos humano ao humanitarismo.

Enfim, um suposto "poder destituinte" necessita resultar na possibilidade de novos começos; isto é, de ações políticas que, em comunidades plurais, inaugurem "teias de relações humanas", na qual as estórias (stories, narrativas) - produtos da ação e do discurso transformam-se, permitindo a todos serem iniciadores de novas ações ${ }^{83}$. A comunidade, quando regida pelo amor mundi, potencialmente rompe as barreiras do essencialismo identitário, propiciando o surgimento de espaços singularmente plurais (não homogêneos, diversos, não tangíveis e sem resultados objetiváveis). Em suma, a “comunidade que vem” certamente terá como principal tarefa a invenção de novas maneiras de exercício da necessidade e ser-estar estar entre os homens.

\section{REFERÊNCIAS}

AGAMBEN, Giorgio. Homo Sacer. O poder soberano e a vida nua I. Belo Horizonte: UFMG, 2004. - Como a obsessão por segurança muda a democracia. Le Monde Diplomatique Brasil. Disponível em: < http://www.diplomatique.org.br/artigo.php?id=1568>. Acesso em: 28.Jun.2014.

. A comunidade que vem. Trad. Antônio Guerreiro. Lisboa: Editorial Presença, 1993.

ARENDT, Hannah. A vida do espírito: o pensar, o querer e o julgar. Rio de Janeiro: Relume Dumara/UFRJ, 1981.

.Origens do Totalitarismo. São Paulo. Companhia das Letras. 1989.

. A condição humana. Rio de Janeiro: Forense Universitária, 2010.

. Homens em tempos sombrios. São Paulo: Companhia das Letras, 1987.

. A promessa da Política. Rio de Janeiro: Difel, 2008.

.Entre o passado e o futuro. São Paulo: Perspectiva, 2005.

BRUHL, Henri Levy. Sociologia do direito. São Paulo: Martins Fontes, 1997.p.20

${ }^{83}$ ARENDT. Op.cit. 2010. P. 230. 
CORREIA, Adriano. A questão Social em Hannah Arendt: apontamentos críticos. Revista de Filosofia Aurora, Curitiba, v. 20, n. 26, 2008. P.101-112.

DANNER, Fernando. O Sentido da Biopolítica em Michel Foucault. Revista Estudos Filosóficos, $\mathrm{n}^{\circ}$ 4, 2010. P.143-157.

DEGRYSE, Annelies. The Sovereign and the Social: Arendt's Understanding of Hobbes. Ethical Perspectives: Journal of the European Ethics Network. Londres, v.15, n.2, 2008. P.239-258.

DRUCKER, Claudia Pellegrini. O destino da tradição revolucionária: auto-incompreensão ou impossibilidade ontológica?. In: MORAES, Eduardo Jardim de; BIGNOTTO, Newton. Hannah Arendt: diálogos, reflexões, memórias. Belo Horizonte: UFMG, 2003.

DUARTE, André. Hannah Arendt e a modernidade: esquecimento e redescoberta da política. Trans/Form/Ação, Marília , v. 24, n. 1, 2001 . Disponível em: <http: / / www.scielo.br/scielo.php?script=sci_arttext\&pid=S010131732001000100017\&lng=en\&nr m=iso>. Acesso em: 29. Set 2014.

FERREIRA FILHO, Manoel Gonçalves. O Poder Constituinte. São Paulo: Saraiva, 1999.

LAFER, Celso. Hannah Arendt: pensamento, persuasão e poder. Rio de Janeiro: Ed. Paz e Terra, 1979.

A reconstrução dos Direitos Humanos. Um diálogo com o pensamento de Hannah Arendt. São Paulo: Companhia das Letras, 1988.

MAGALHÃES, Juliana Neuenschwander. O paradoxo dos Direitos Humanos. Revista da Faculdade de Direito - UFPR, Curitiba, n.52, 2010. P.31-48.

PEREIRA, Geraldo Adriano. A “tensão” como um operador hermenêutico para uma racionalidade política em Hannah Arendt. Philósophos - Revista de Filosofia, Goiânia, v.11, n.1, 2006. Disponível em: <http://www.revistas.ufg.br/index.php/philosophos/ article/view/3709>. Acesso em: 28.Mai.2015.

PITKIN, Hannah Fenichel. The Attack of the Blob: Hannah Arendt's Concept of the Social. Chicago: University of Chicago Press, 1998.

SARLET, Ingo Wolfgang. A Eficácia dos Direitos Fundamentais. Porto Alegre: Livraria do Advogado, 2005.

SCHIO, Sônia Maria. Hannah Arendt: história e liberdade: da ação a reflexão. Porto Alegre: Clarinete, 2012. ; PEIXOTO, Claudia Carneiro. O conceito de lei em Hannah Arendt. ethic@ - Florianópolis, v.11, n.3, 2012. P. 289 - 297.

WAGNER, Eugênia Sales. Hannah Arendt e Karl Marx: o mundo do trabalho. São Paulo: Ateliê Editorial, 2002. P.144.

Recebido em: 30/04/2015 / Revisões requeridas em: 16/09/2015 / Aprovado em: 27/10/2015 